\title{
Acute Complications of Diabetes and its Predictors among Adult Diabetic Patients at Jimma Medical Center, Southwest Ethiopia
}

This article was published in the following Dove Press journal:

Diabetes, Metabolic Syndrome and Obesity: Targets and Therapy

\author{
Getandale Zeleke Negera $\mathbb{D}^{\prime}$ \\ Belachew Weldegebriel (iD' \\ Ginenus Fekadu (D) ${ }^{2}$ \\ 'Department of Clinical Pharmacy, \\ School of Pharmacy, Institute of Health, \\ Jimma University, Jimma, Ethiopia; \\ ${ }^{2}$ Department of Clinical Pharmacy, \\ School of Pharmacy, Institute of Health \\ Sciences, Wollega University, Nekemte, \\ Ethiopia
}

Background: Diabetes mellitus (DM) is a group of metabolic disorders characterized by hyperglycemia resulting from impairment in insulin secretion, insulin action, or both. It is responsible for a wide range of acute and chronic complications. In this study, we aimed to assess acute complications of diabetes and its predictors among adult DM patients at Jimma Medical Center (JMC), southwest Ethiopia.

Methods: A facility-based cross-sectional study involving 348 diabetic patients was conducted from February to May 31, 2019 at JMC. Logistic regression was conducted to identify predictors of acute complications of diabetes. Variables with $P \leq 0.25$ on bivariate logistic regression were considered candidates for multivariate regression. ORs and $95 \%$ CIs with $P<0.05$ were considered statistically significant.

Results: Of the 348 patients, 225 (64.7\%) were male, and the mean age of study participants was $46 \pm 15.5$ years. Most $(281,80.7 \%)$ had type 2 DM. More than two-thirds $(240,69 \%)$ had diabetes duration of $<5$ years. During the study period, 92 (26.4\%) patients developed acute complications of diabetes. Of these, 68 (73.9\%) had diabetic ketoacidosis, 21 (22.8\%) a hyperglycemic hyperosmolar state, and three (3.3\%) hypoglycemia. Presence of comorbidity (AOR 5.6, 95\% CI 2.80-11.19), type 1 DM (AOR 9.3, 95\% CI 4.36-19.82), uncontrolled blood glucose (AOR 1.91, 95\% CI 1.05-3.45), and lack of access to a health facility within a reasonable distance (AOR 1.96, 95\% CI 1.11-3.45) were independent predictors of acute complications of diabetes.

Conclusion: The magnitude of acute complications among DM patients at JMC was high. Comorbidity, type $1 \mathrm{DM}$, uncontrolled blood sugar, and lack of access to a health facility within a reasonable distance were independent predictors of acute complications. Clinicians should follow up this subgroup of DM patients closely.

Keywords: acute complications, diabetic ketoacidosis, hyperglycemic hyperosmolar state, Ethiopia

\section{Background}

Diabetes mellitus (DM) is a metabolic disorder characterized by persistently elevated blood glucose associated with absent or inadequate pancreatic insulin secretion, with or without concurrent impairment of insulin action. DM can be either type 1 (T1D) or (T2D). ${ }^{1,2} \mathrm{DM}$ is frequently associated with deadly acute complications if not diagnosed early and managed rigorously. Diabetic ketoacidosis (DKA) and hyperglycemic hyperosmolar state (HHS) are the two most common lifethreatening acute metabolic complications of $\mathrm{DM}^{3}$ Some patients have already
Correspondence: Getandale Zeleke Negera

Department of Clinical Pharmacy, School of Pharmacy, Institute of Health Jimma University, PO Box 378, Jimma, Ethiopia Tel +25I 912892539

Email getandale@gmail.com 
developed these complications when they first visit a health facility and are diagnosed with DM. This might be due to susceptible groups' failure to take frequent health checkups and screening tests. Others obviously develop complications as a result of inadequate glycemic control in the treatment process. ${ }^{4,5}$

DKA most often occurs in T1D and is one of the most serious acute complications of DM. DKA may be the initial symptom complex that leads to a diagnosis of T1D, but more frequently it occurs in individuals with established DM. As it is a severe illness that requires immediate intervention and careful management, its mortality rate is higher in developing countries $-2 \%-5 \%{ }^{6-}$ ${ }^{8} \mathrm{HHS}$ is also a medical emergency, but typically occurs in the elderly and sometimes in young adults and teenagers as an initial presentation of T2D. HHS has a higher mortality rate of up to $15 \%$ - that is significantly higher than mortality for DKA. The most serious complications of both HHS and DKA are cerebral edema and acute respiratory distress syndrome. ${ }^{7,9}$

The prevalence of DM has increased rapidly in the last two decades in Ethiopia, posing a significant economic burden. ${ }^{10}$ Glycemic control and prevention of subsequent acute complications is hampered by economic constraints and inadequate supply of anti-DM medications. As a result, a majority of DM patients in Ethiopia receive substandard DM care. ${ }^{11,12}$ Furthermore, access to comprehensive education about DM self-management and blood-glucose monitoring is low in the country, contributing to poor glycemic control. Studies conducted in some parts of the country have reported that $95 \%$ of DM patients do not perform self-blood glucose monitoring at home, and $33 \%$ do not adhere to their medications. ${ }^{13,14}$ Reports have shown that up to $4.4 \%$ of all in-hospital admissions are caused by DM-related complications leading to $3.4 \%-32.5 \%$ total deaths. ${ }^{15-17}$ Since studies are scarce in this area, ${ }^{18}$ this study was designed to determine the prevalence of acute complications of DM and contributing factors at Jimma Medical Center (JMC), southwest Ethiopia. The findings of this study should help health professionals and policy-makers in designing appropriate intervention strategies to tackle the problem.

\section{Methods}

\section{Study Design and Setting}

This facility-based cross-sectional study was conducted from February to May 31, 2019 in the diabetic clinic of JMC. JMC is located in the town of Jimma, $355 \mathrm{~km}$ from
Addis Ababa. It is currently the only teaching and specialized hospital in the southwest region of Ethiopia. The hospital serves as a referral site and provides specialized care for southwest Ethiopia, with a catchment population of about 15 million.

\section{Study Population and Variables}

We included all adult (age $>18$ years) DM patients who had follow-up at the diabetic clinic during the study period. Unconscious, psychotic, and pregnant patients were excluded. Data were collected on sociodemographic characteristics: age, sex, area of residence, monthly income, body-mass index (BMI), social drug use (chewing khat, smoking), diseases related factors (type of DM, duration of DM, family history of DM), treatment-related factors (types of anti-DM drugs), and acute complications of DM (DKA, HHS, and hypoglycemia).

\section{Sample-Size Determination and Sampling Technique}

The minimum sample size was calculated using the formula $\mathrm{n}=\mathrm{z} 2 \mathrm{pq} / \mathrm{d} 2$, where, $\mathrm{n}$ is the required sample size, $\mathrm{p}$ expected prevalence of acute complications of DM, $50 \%$, ie, $\mathrm{q}=1-\mathrm{p}$ and d error (precision), ie, $5 \% .{ }^{19}$ As such, the sample size calculated was 312 , and with $10 \%$ contingency the final sample size was 348. Simple random sampling was used to select patients using computer-generated random numbers.

\section{Data-Collection Tool and Procedure}

The data-collection tool was developed based on previous similar studies and patient follow-up charts. It was originally prepared in English, then translated to local languages (Oromo and Amharic) and back-translated to English by independent language experts to ensure the translated version gave the proper meaning. The questionnaire consisted of two sections: section one assessed sociodemographic and behavioral characteristics, and section two included questions regarding clinical and drug-related characteristics.

For section one, the socio-demographic and behavioral data collected were age, sex, BMI, marital status, area of residence, occupation, education, monthly income, smoking status, and khat chewing. Section two consisted of questions regarding clinical and drug-related characteristics, namely family history of DM, comorbidities, duration of DM, type of DM, type of regimen, status of glycemic control, and type of acute complications. The questionnaire was evaluated for 
face validity by a team of endocrinologists and public health specialists. After consideration of comments of the team, a pilot study was conducted on 35 patients $(10 \%$ of the sample size), based on which final revisions to the questionnaire were made for clarity and understandability. Data were collected through face-to-face interviews by four trained nurses and two supervisors.

\section{Data-Quality Assurance}

The quality of data was assured by properly designing the tool, the questionnaire was pretested in JMC, and important modifications were made prior to actual data collection. Two days' training was provided to the data collectors and supervisors on the data-collection tool, how to ask questions, and ways of approaching respondents. The data collected were checked carefully on a daily basis for completeness, accuracy, and clarity by a supervisor, and the principal investigators monitored the overall activities of data collection.

\section{Statistical Analysis}

Data were entered into EpiData 3.2 and exported to SPSS version 21.0 for cleaning and analysis. Descriptive analysis was performed, and results are presented by text and tables. $\chi^{2}$ tests were performed to check the adequacy of cells before performing logistic regression. Bivariate and multivariate logistic regression was carried out to assess independent predictors of acute complications of DM. Bivariate logistic regression was performed to identify candidate variables for multivariate logistic regression. Variables with $P \leq 0.25$ on bivariate regression were considered as candidates for multivariate regression. We checked multicollinearity among selected independent variables via the variance-inflation factor, and none was found. Multivariate logistic regression was performed using a backward method to identify independent predictors. ORs and $95 \%$ CIs were obtained, and $P \leq 0.05$ was taken as indicating statistical significance.

\section{Ethical Approval and Consent to Participate}

Signed informed consent was taken from all participants prior to data collection, and the study was conducted in accordance with the Declaration of Helsinki. Anonymity and confidentiality of data were assured. The study was approved by Institutional Review Board (IRB) of the Institute of Health, Jimma University.

\section{Operational Definition of Terms}

- Controlled blood sugar: fasting blood sugar 80-130 $\mathrm{mg} / \mathrm{dL}{ }^{20}$

- Acute complications of DM: one of three complications diagnosed by physicians, ie, DKA/HHS/ hypoglycemia.

- Khat chewing: chewing the leaves of the khat plant in any amount.

\section{Results}

\section{Sociodemographic and Behavioral Characteristics of Study Participants}

During the study period, a total of 348 adult DM patients were included. A majority $(225,64.7 \%)$ were male. The mean age of participants was $46 \pm 15.5$ years. A majority $(202,58 \%)$ were urban dwellers. Mean BMI was $25.4 \pm 3.2 \mathrm{~kg} / \mathrm{m}^{2}$. A third of the participants (34.5\%) were merchants, and $134(38.5 \%)$ had an average monthly income of ETB1,500-3,000 (Table 1).

Table I Sociodemographic, and Behavioral Characteristics of the Adult Diabetic Patients at Jimma Medical Center, Southwest Ethiopia, 2019

\begin{tabular}{|c|c|c|}
\hline & & Frequency (\%) \\
\hline Sex & $\begin{array}{l}\text { Male } \\
\text { Female }\end{array}$ & $\begin{array}{l}225(64.7) \\
123(35.3)\end{array}$ \\
\hline Age (years) & $\begin{array}{l}18-25 \\
26-50 \\
>50 \\
\text { Mean } \pm \text { SD }\end{array}$ & $\begin{array}{l}43(12) \\
170(48.8) \\
135(38.9) \\
46 \pm 15.5\end{array}$ \\
\hline Body-mass index & Mean $\pm \mathrm{SD}(\mathrm{kg} / \mathrm{m} 2)$ & $25.4 \pm 3.2$ \\
\hline Residence & $\begin{array}{l}\text { Urban } \\
\text { Rural }\end{array}$ & $\begin{array}{l}202(58) \\
146(42)\end{array}$ \\
\hline Education & $\begin{array}{l}\text { Illiterate } \\
\text { Primary } \\
\text { Secondary } \\
\text { Tertiary }\end{array}$ & $\begin{array}{l}6(1.7) \\
84(24.1) \\
160(46.0) \\
98(28.2)\end{array}$ \\
\hline Monthly income & $\begin{array}{l}\leq \mathrm{ETB} 3,000 \text { (US\$86.2) } \\
>\mathrm{ETB} 3,000 \text { (US\$86.2 USD) }\end{array}$ & $\begin{array}{l}241(69.7) \\
107(30.7)\end{array}$ \\
\hline Occupation & $\begin{array}{l}\text { Farmer } \\
\text { Merchant } \\
\text { Student } \\
\text { Government employee } \\
\text { Retired }\end{array}$ & $\begin{array}{l}79(23) \\
120(34.5) \\
40(11.5 \%) \\
77(22 \%) \\
2(0.5)\end{array}$ \\
\hline Smoking & $\begin{array}{l}\text { Smoker } \\
\text { Non/exsmoker }\end{array}$ & $\begin{array}{l}42(12.1 \%) \\
306(87.9)\end{array}$ \\
\hline Khat chewing & $\begin{array}{l}\text { Yes } \\
\text { No }\end{array}$ & $\begin{array}{l}218(62.6) \\
130(37.4)\end{array}$ \\
\hline
\end{tabular}




\section{Clinical and Drug-Related Characteristics}

More than two-thirds, $(240,69 \%)$ of patients had had DM $<5$ years, and 87 (25\%) had a family history of DM. Most (281, 80.7\%) had T2D, and the remaining 67 (19.3\%) T1D. Among the total participants, 195 (56\%) used oral hypoglycemic agents, 92 (26.4\%) insulin only, and $61(17.5 \%)$ used both oral hypoglycemic agents and insulin. Concerningblood-glucose levels, a majority $(246,71 \%)$ had controlled blood sugar. During the study period, 92 (26.4\%) patients developed acute complications. Of these, 68 (73.9\%) had DKA, 21 (22.8\%) HHS, and three (3.3\%) had hypoglycemia (Table 2 ).

\section{Predictors of Acute Complications of Diabetes}

Binary logistic regression was performed to identify associations between sociodemographic and clinical characteristics and acute complications. Age, BMI, comorbidities, type of

Table 2 Clinical and Drug-Related Characteristics of the Adult DM Patients at Jimma Medical Center, Southwest Ethiopia, 2019

\begin{tabular}{|c|c|c|}
\hline & & $\begin{array}{l}\text { Frequency } \\
\text { (\%) }\end{array}$ \\
\hline Family history of DM & $\begin{array}{l}\text { Yes } \\
\text { No }\end{array}$ & $\begin{array}{l}26 \mid(75) \\
87(25)\end{array}$ \\
\hline Duration of DM (years) & $\begin{array}{l}\leq 5 \\
>5\end{array}$ & $\begin{array}{l}240(69) \\
108(31)\end{array}$ \\
\hline Type of DM & $\begin{array}{l}\text { Type } 1 \\
\text { Type } 2\end{array}$ & $\begin{array}{l}67(19.3) \\
281(80.7)\end{array}$ \\
\hline Type of regimen & $\begin{array}{l}\text { Oral hypoglycemic } \\
\text { agents } \\
\text { Insulin only } \\
\text { Oral hypoglycemic } \\
\text { agents and insulin }\end{array}$ & $\begin{array}{l}195(56) \\
92(26.4) \\
61(17.5)\end{array}$ \\
\hline Glycemic control & $\begin{array}{l}\text { Controlled } \\
\text { Uncontrolled }\end{array}$ & $\begin{array}{l}246(7 I) \\
102(29)\end{array}$ \\
\hline Acute complication(s) & $\begin{array}{l}\text { Yes } \\
\text { No }\end{array}$ & $\begin{array}{l}92(26.4) \\
256(73.6)\end{array}$ \\
\hline Type of acute complication & $\begin{array}{l}\text { DKA } \\
\text { HHS } \\
\text { Hypoglycemia }\end{array}$ & $\begin{array}{l}68(73.9) \\
21(22.8) \\
3(3.3)\end{array}$ \\
\hline Comorbidities & $\begin{array}{l}\text { Yes } \\
\text { No }\end{array}$ & $\begin{array}{l}196(56.3) \\
152(43.7)\end{array}$ \\
\hline $\begin{array}{l}\text { Access to health facility } \\
\text { within a reasonable distance }\end{array}$ & $\begin{array}{l}\text { Yes } \\
\text { No }\end{array}$ & $\begin{array}{l}215(61.8) \\
133(38.2)\end{array}$ \\
\hline
\end{tabular}

Abbreviations: DM, diabetes mellitus; DKA, diabetic ketoacidosis; HHS, hyperglycemic hyperosmolar state.
DM, status of glycemic control, and access to health facilities showed $P<0.25$. On multivariate logistic regression modeling, comorbidity (AOR 5.6, 95\% CI 2.80-11.19; $p<0.001$ ), T1D (AOR 9.3, 95\% CI 4.36-19.82; $p<0.001$ ), uncontrolled blood glucose (AOR 1.91, 95\% CI 1.05-3.45; $p=0.03$ ), and lack of access to a health facility within a reasonable distance (AOR $1.96,95 \%$ CI 1.11-3.45; $p=0.01)$ remained significant predictors of acute complications of DM (Table 3).

\section{Discussion}

This study investigated the prevalence of acute complications of DM and contributing factors in a tertiary-care hospital. The prevalence of acute complications of DM was 92 (26.4\%). Comorbidities, T1D, uncontrolled blood sugar, and lack of access to health facilities within a reasonable distance were independent predictors of acute complications. Males had predominance over females, and this might be related to the relatively higher number of male DM patients in the study area. A similar finding was reported by Worku et $\mathrm{al}^{18}$ in the same study area.

Acute complications of DM occurred in $26.4 \%$ of patients, and DKA was the most common. This is similar to studies conducted in northeast Ethiopia ${ }^{21}$ and Taiwan. ${ }^{22}$ There are lots of contributing factors to DM-related complications in our study area. Notably, Negera et $\mathrm{al}^{23}$ showed that a majority of DM patients at JMC were nonadherent to lifestyle-modification recommendations, which are of paramount importance in preventing DM-related complications. DM patients with comorbidities were five times as likely to develop acute complications than patients without comorbidities (AOR 5.6, 95\% CI 2.80-11.19). This is in line with the findings of Ponesai et al. ${ }^{24}$ The presence of comorbidities can have a debilitating impact on glycemic control and subsequent acute complications by increasing the cost and time of treatment, which reduces the amount of time and energy left for DM care. ${ }^{25,26}$

Type of DM was another predictor of acute complication. T1D patients were at higher risk of developing them. This is consistent with a report of the American Diabetes Association. Absolute deficiency of insulin in T1D patients makes them prone to acute complications even with the missing of a single insulin dose. ${ }^{27}$ Our finding contradicts a study in Gondar, ${ }^{28}$ where T2D patients had a higher risk of complications. Differences in study design and definition of complications may be the possible reasons for this.

Acute complications were higher in DM patients with uncontrolled blood glucose than their counterparts, similar to studies conducted in Brazil ${ }^{29}$ and Arbaminch, Ethiopia. ${ }^{30}$ It is obvious that DM patients with uncontrolled blood 
Table 3 CORs and AORs for Predictors of Acute Complications Among Adult DM Patients at Jimma Medical Center, Southwest Ethiopia, 2019

\begin{tabular}{|c|c|c|c|c|c|c|}
\hline & & \multicolumn{2}{|c|}{ Acute Complications of DM } & \multirow[t]{2}{*}{ COR $(95 \% \mathrm{Cl})$} & \multirow[t]{2}{*}{ AOR $(95 \% \mathrm{Cl})$} & \multirow[t]{2}{*}{$p$-value } \\
\hline & & Yes & No & & & \\
\hline $\begin{array}{l}\text { Age, mean } \pm S D, \text { (years) } \\
\text { BMI, mean } \pm S D,\left(\mathrm{~kg} / \mathrm{m}^{2}\right)\end{array}$ & & $\begin{array}{l}41 \pm 16.01 \\
24.34 \pm 3.32\end{array}$ & $\begin{array}{l}47 \pm 13.70 \\
25.68+3.08\end{array}$ & $\begin{array}{l}0.96(0.95-0.98) \\
0.87(0.80-0.94)\end{array}$ & $\begin{array}{l}0.99(0.97-1.02) \\
0.92(0.85-1.01)\end{array}$ & $\begin{array}{l}0.87 \\
0.08\end{array}$ \\
\hline Comorbidity & $\begin{array}{l}\text { Yes } \\
\text { No }\end{array}$ & $\begin{array}{l}165 \\
101\end{array}$ & $\begin{array}{l}31 \\
51\end{array}$ & $\begin{array}{l}2.8(1.6 I-4.47) \\
I\end{array}$ & $\begin{array}{l}5.6(2.80-11.19) \\
1\end{array}$ & $<0.001 *$ \\
\hline Access to health facility & $\begin{array}{l}\text { Yes } \\
\text { No }\end{array}$ & $\begin{array}{l}82 \\
89\end{array}$ & $\begin{array}{l}133 \\
44\end{array}$ & $2.30(1.39-3.80)$ & $1.96(1.11-3.45)$ & $\begin{array}{l}1 \\
0.01 *\end{array}$ \\
\hline Type of DM & $\begin{array}{l}1 \\
2\end{array}$ & $\begin{array}{l}42 \\
98\end{array}$ & $\begin{array}{l}25 \\
183\end{array}$ & $\begin{array}{l}5.00(2.82-8.85) \\
\text { I }\end{array}$ & $\begin{array}{l}9.30(4.36-19.82) \\
\text { I }\end{array}$ & $\begin{array}{l}<0.00 I^{*} \\
\mathrm{I}\end{array}$ \\
\hline Glycemic control & $\begin{array}{l}\text { Controlled } \\
\text { Uncontrolled }\end{array}$ & $\begin{array}{l}88 \\
69\end{array}$ & $\begin{array}{l}158 \\
33\end{array}$ & $\begin{array}{l}1 \\
1.92(1.14-3.23)\end{array}$ & $\begin{array}{l}\text { I } \\
1.91(1.05-3.45)\end{array}$ & $\begin{array}{l}\text { I } \\
0.03 *\end{array}$ \\
\hline
\end{tabular}

Note: $*_{p}<0.05$.

Abbreviations: AOR, adjusted OR; BMI, body-mass index; COR, crude O; DM, diabetes mellitus.

glucose are at high risk of a wide variety of DM-related complications. Moreover, DM patients who lack access to a health facility within a reasonable distance have a higher risk of developing acute complications. A study conducted in Zimbabwe also found that DM patients residing $5 \mathrm{~km}$ or more from a hospital were more likely to develop complications than those who resided within a $5 \mathrm{~km}$ radius. ${ }^{24}$ Our study is not free of limitations. We enrolled participants from only one institution, and hence our findings cannot be generalized to other DM patients. Outcomes of complications were not determined. Moreover, the nature of the cross-sectional study design does not indicate a temporal relationship or causality.

\section{Conclusion}

In the current study, the magnitude of acute DM complications at JMC was high. Predictors of acute complications were comorbidities, T1D, uncontrolled blood sugar, and lack of access to health facilities within a reasonable distance. Clinicians should follow up this subgroup of DM patients closely.

\section{Abbreviations}

DM, diabetes mellitus; DKA, diabetic ketoacidosis; HHS, hyperglycemic hyperosmolar state; JMC, Jimma Medical Center.

\section{Data-Sharing Statement}

The data sets used and/or analyzed during the current study are available from the corresponding author on reasonable request.

\section{Acknowledgments}

The authors thank the study participants, data collectors, and all staff members of Jimma Medical Center for their kind cooperation in conducting this thesis. We also would like to thank Jimma University for allowing us to conduct this research.

\section{Author Contributions}

All authors made substantial contributions to conception and design, acquisition of data, analysis and interpretation of data, drafting the manuscript, revising the manuscript critically, reading and approving the final draft submission, gave final approval of the manuscript version to be published, and agreed to be accountable for every step of the work.

\section{Disclosure}

The authors report no funding and no conflicts of interest for this work.

\section{References}

1. Diabetes CJ. Definition, classification and diagnosis of diabetes, prediabetes and metabolic syndrome [Internet]. 2013. Available from: https://www.ncbi.nlm.nih.gov/pubmed/24070969. Accessed April 7, 2020.

2. Ding Y, Tanaka Y, Wu Y, et al. Risk factors contributing to type 2 diabetes and recent advances in the treatment and prevention. Int $J$ Med Sci. 2014;11(11):1185-1200. doi:10.7150/ijms.10001

3. Kitabchi AE, Umpierrez GE, Miles JM, Fisher JN. Hyperglycemic crises in adult patients with diabetes: a consensus statement from the American Diabetes Association. Diabetes Care. 2009;32(7):13351343. doi: $10.2337 / \mathrm{dc} 09-9032$ 
4. Al Qahtani MA, Shati AA, Alsuheel AM, et al. Diabetic ketoacidosis as an initial presentation of type-1 diabetic children in aseer region of Saudi Arabia. Int J Curr Res Rev. 2013;5(20):41-46.

5. Balmier A, Dib F, Serret-Larmande A, et al. Initial management of diabetic ketoacidosis and prognosis according to diabetes type: a French multicentre observational retrospective study. Ann Intensive Care. 2019;9(91). doi:10.1186/s13613-019-0567-y

6. Graves EJ, Gillum BS. Detailed diagnoses and procedures, National Hospital Discharge Survey, 1995. Vital Health Stat. 1997;13(130):1146.

7. Kitabchi AE, Umpierrez GE, Murphy MB, et al. Management of hyperglycemic crises in patients with diabetes. Diabetes Care. 2001;24(1):131-153. doi:10.2337/diacare.24.1.131

8. Kasper DL, Hauser SR, Jameson JL, Fausi AS, Longo DL, Loskalzo J. Harrison's Principles of Internal Medicine (19thed.). New York: McGraw Hill Education; 2015.

9. Kitabchi AE, Umpierrez GE, Murphy MB, Kreisberg R Hyperglycemic crises in adult patients with diabetes. A consensus statement from the American Diabetes Association [Internet]. Available from: http://care.diabetesjournals.org/content/29/12/2739. Accessed April 7, 2020.

10. Feleke Y, Enquselassie F. Cost of hospitalization of diabetic patients admitted at Tikur Anbessa Specialized Hospital, Addis Ababa, Ethiopia. Ethiop Med J. 2007;45(3):275-282.

11. Lester FT. Ketoacidosis in Ethiopian diabetics. Diabetol. 1980;18 (5):375-377.

12. Nigatu T. Epidemiology, complications and management of diabetes in Ethiopia: a systematic review. J Diabetes. 2012;4(2):2011-2012. doi:10.1111/j.1753-0407.2011.00181.x

13. Lester FT. The clinical pattern of diabetes mellitus in Ethiopians. Diabetes Care. 1984;7(1):6-11. doi:10.2337/diacare.7.1.6

14. Feleke Y, Enquselassie F. An assessment of the health care system for diabetes in Addis Ababa, Ethiopia. Ethiop J Health Dev. 2005;19 (3):203-210.

15. Ajayi EA, Ajayi AO. Pattern and outcome of diabetic admissions at a federal medical center: a 5-year review. Ann Afr Med. 2009;8(4):271275. doi:10.4103/1596-3519.59584

16. Chijioke A, Adamu AN, Makusidi AM. Mortality patterns among type 2 diabetes mellitus patients in Ilorin, Nigeria. J Endocrinol Metab Diabetes South Africa. 2010;15(2):79-82. doi:10.1080/ 22201009.2010.10872231

17. Bradshaw D, Pillay-van Wyk V, Laubscher R, et al. Cause of Death Statistics for South Africa: Challenges and Possibilities for Improvement. South Africa Burden of Disease Research Unit; 2010.
18. Worku D, Hamza L, Woldemichael K. Patterns Of Diabetic Complications At Jimma University Specialized Hospital, Southwest Ethiopia. Ethiop J Health Sci. 2010;20(1):33-39.

19. Lwanga SK, Lemeshow S. Sample Size Determination for Health Studies: A Practical Manual. Geneva: World Health Organization; 1991:1-5.

20. American Diabetes Association. Glycemic targets: standards of medical care in diabetes. Diabetes Care. 2019;42(1):S61-70. doi:10.2337/dc19-S006

21. Abejew AA, Belay AZ, Kerie MW. Diabetic complications among adult diabetic patients of a tertiary hospital in Northeast Ethiopia. Adv Public Health. 2015;2015:1-7. doi:10.1155/2015/290920

22. Huang-Tz O, Lee T-Y, Chung-Yi L, et al. Incidence of diabetesrelated complications in Chinese patients with type 1 diabetes: a population-based longitudinal cohort study in Taiwan. Diabetes Endocrinol Res. 2017;7(6):1-11.

23. Negera GZ, Charles D. Prevalence and predictors of nonadherence to diet and physical activity recommendations among type 2 diabetes patients in Southwest Ethiopia: a cross-sectional study. Int $J$ Endocrinol. 2020;2020:1512376.

24. Ponesai N, Anderson C, Mufuta T, et al. Risk factors for diabetic complications among diabetic patients, Chirumanzu District, Zimbabwe, 2011. Austin J Public Health Epidemiol. 2015;2(2):1-7.

25. Bayliss EA, Steiner JF, Fernald DH, Crane LA, Main DS. Descriptions of barriers to self-care by persons with comorbid chronic diseases. Ann Fam Med. 2003;1:15-21. doi:10.1370/afm.4

26. Rogowsky J, Lillard LA, Kington R. The financial burden of prescription drug use among elderly persons. Gerontologist. 1997;37:475-482. doi:10.1093/geront/37.4.475

27. American diabetes association. Standards of medical care in diabetes. Diabetes Care. 2020;43:S1-S139. doi:10.2337/dc20-Sint

28. Fasil A, Biadgo B, Abebe M. Glycemic control and diabetes complications among diabetes mellitus patients attending at University of Gondar Hospital, Northwest Ethiopia. Diabetes Metab Syndr Obes Targets Ther. 2019;12:75-83. doi:10.2147/DMSO.S185614

29. Lima VC, Cavalieri GC, Lima MC, Nazario NO, Lima GC. Risk factors for diabetic retinopathy: a case-control study. Int J Retin Vitr. 2016;2(1):21. doi:10.1186/s40942-016-0047-6

30. Chisha Y, Terefe W, Assefa H, Lakew S. Prevalence and factors associated with diabetic retinopathy among diabetic patients at Arbaminch General Hospital, Ethiopia: cross sectional study. PLoS One. 2017;12(3):e0171987. doi:10.1371/journal.pone.0171987

\section{Publish your work in this journal}

Diabetes, Metabolic Syndrome and Obesity: Targets and Therapy is an international, peer-reviewed open-access journal committed to the rapid publication of the latest laboratory and clinical findings in the fields of diabetes, metabolic syndrome and obesity research. Original research, review, case reports, hypothesis formation, expert opinion and commentaries are all considered for publication. The manuscript management system is completely online and includes a very quick and fair peer-review system, which is all easy to use. Visit http://www.dovepress.com/testimonials.php to read real quotes from published authors. 